\title{
TECENDO UMA CULTURA INTRAEMPREENDEDORA: O CASO DA DIKLATEX TÊXTIL
}

Paula Daiane Loch $^{1}$

Gustavo Behling ${ }^{1}$

Carlos Marcelo Ardigó ${ }^{1}$

${ }^{1}$ Universidade do Vale do Itajaí 


\section{TECENDO UMA CULTURA INTRAEMPREENDEDORA: O CASO DA DIKLATEX TÊXTIL}

Resumo: A Diklatex Têxtil é uma malharia localizada em Joinville (SC) focada na oferta de tecidos tecnológicos para os segmentos de activewear, sportwear e beachwear. Recém-saída de um longo período de crise, a empresa elaborou um novo planejamento estratégico que trouxe à tona a necessidade de inovar. Porém, os sucessivos anos sem investimentos na inovação e de clima organizacional ruim em razão da crise, torna difícil a retomada da cultura inovativa e intraempreendedora dos colaboradores. Como tornar a Diklatex uma empresa com uma cultura voltada à inovação, é o principal dilema deste caso, que pode ser utilizado em cursos de especialização, MBAs ou graduação na área da gestão em disciplinas como Empreendedorismo, Inovação e Cultura Organizacional. As situações relatadas neste caso são baseadas em uma estória real e o nome da empresa e dos empreendedores foram mantidos. As notas de ensino trazem sugestões de questões a serem discutidas em sala.

Palavras-chave: Intraempreendedorismo. Inovação. Cultura intraempreendedora. Cultura organizacional.

\section{$1 \quad$ Introdução}

Um longo período de tempo passando por dificuldades financeiras, com uma sucessão de resultados negativos. A motivação dos funcionários abalada com a falta de recursos e com o corte de investimentos. Teria esse período turbulento da história da Diklatex reduzido a atitude intraempreendedora dos seus colaboradores e a capacidade de inovação da empresa?

Era uma pergunta que Andre, diretor da empresa e filho dos fundadores, se fazia e para a qual tinha certeza da resposta... Mas o que poderia ser feito dali para a frente para que a empresa tivesse uma cultura intraempreendedora? Engajar 185 colaboradores e 14 gestores para que se sintam "donos do negócio", não era uma tarefa fácil.

Depois de dois anos consecutivos de resultados positivos e da elaboração de um novo planejamento estratégico que demonstrou a importância de a Diklatex inovar, essa não é apenas uma vontade dos sócios, mas sim o caminho para o futuro da companhia.

\section{As raízes tecnológicas da Diklatex}

A Diklatex é atualmente uma das grandes empresas têxteis de Santa Catarina, focada no desenvolvimento de tecidos tecnológicos para os segmentos de activewear, sportwear e beachwear. Mas a sua história começou a ser construída muito antes de ser adquirida pelo seu atual proprietário, Mauricio Jativa e sua família.

A empresa foi fundada em 1978, com o objetivo de produzir tecidos sintéticos para lingerie e atender o mercado nacional. Em 1987, mudou totalmente o foco e se especializou na produção de tecidos para tênis, passando a atender a indústria calçadista. Neste período o parque fabril foi ampliado com a aquisição de teares de malharia alemã permitindo à empresa um pioneirismo no segmento que se mantém até os dias de hoje.

Outra indústria têxtil, a Brapa, com sede em São Paulo, produzia tecidos para marcas esportivas e devido ao aumento no consumo das camisas de futebol feitas com tecidos $100 \%$ 
sintéticos, a empresa transferiu sua sede para Joinville (SC), fazendo fortes investimentos no seu parque fabril e aumentando significativamente a sua produtividade.

Por estarem na mesma cidade, o destino das empresas se cruzou e em abril de 2001 as duas malharias se fundiram, nascendo a Diklatex Industrial Têxtil Ltda. O objetivo desta nova companhia era implantar um parque fabril para tingimento e acabamento de tecidos sintéticos como poliéster, poliamida e elastano. Dois anos depois, dada a rápida expansão, a empresa foi transferida para uma nova sede, em uma área de $170 \mathrm{mil} \mathrm{m}^{2}$ localizada na Zona Industrial Norte de Joinville, ganhando ainda mais em capacidade instalada e produtividade. Foi esse know-how com tecidos sintéticos da Diklatex que, em 2007, atraiu o interesse do Sr. Mauricio Jativa, empresário de Brusque (SC) com ampla experiência no ramo têxtil.

\section{Um pouco sobre os Jativas}

Mauricio Jativa, veio do Equador para o Brasil em 1985 para estudar Administração de Empresas na Universidade Federal do Paraná, através de um programa de cooperação entre os dois países. Foi na capital paranaense que o equatoriano conheceu a esposa brusquense Jaqueline Gamba Jativa, estudante de psicologia. O amor pelo Brasil e pela namorada, falou mais forte ao final do curso. Foi quando o sogro lhe fez a proposta de ficar por aqui e iniciar um negócio. Aí, Santa Catarina entrou na vida de Maurício.

Chegando no estado, foi morar na cidade de Brusque com os sogros. Começou a trabalhar na confecção da família de Jaqueline onde aprendeu sobre o mercado têxtil. Seu olhar empreendedor e visionário o fizeram identificar oportunidades de negócios, entre elas, a que mais lhe chamou a atenção: a comercialização de tecidos.

Pouco tempo depois, em 1989, Maurício Jativa fundou sua primeira malharia, a Latina Têxtil, nos fundos de uma estrebaria em terreno cedido pelo sogro. Neste mesmo ano, o berço carregado por Jaqueline, levava Andre, o filho mais velho do casal, para dentro da fábrica, onde ele foi criado e cresceu em meio aos rolos de malhas.

Com uma produção ainda pequena, o sonho do casal ia ganhando forma e a vontade de ter uma grande empresa e empregar muita gente também.

“- Que bons tempos eram aqueles, não eram necessárias muitas contas, afinal o momento era propício para o novo investimento: pouca concorrência e muita demanda no mercado", relembra o empresário.

Com muito esforço, pouco a pouco, o pequeno rancho do sogro foi dando espaço ao que se tornou anos depois uma das maiores empresas têxteis de Brusque e região.

\section{Novas oportunidade e desafios para a família}

No ano de 2006, o casal Jativa já começava a traçar novos ideais. Na época ouviam falar muito sobre o mercado de tecidos de fibras sintéticas, como o poliéster e a poliamida. E foi aí que a veia empreendedora do Sr. Maurício pulsou mais forte novamente, quando o empresário vislumbrou a oportunidade de entrar em um outro segmento: o mercado esportivo.

Em 2007 surgiu a oportunidade de adquirir outra empresa, a Diklatex Industrial Têxtil, com sede na cidade vizinha de Joinville.

“- Quando fomos até Joinville conhecer a Diklatex, foi deslumbrante, era um sonho de empresa, o complemento que precisávamos para a Latina.", comenta Mauricio. 
Junto ao desafio de entender o mercado esportivo, até então desconhecido pelo casal, veio também a necessidade de conhecer e aprender a trabalhar com produtos de valor agregado, atender grandes marcas e confecções, diferentemente do que era conhecido até então no mercado da Latina Têxtil, que sempre teve o foco voltado para o mercado popular atacadista.

Nem tudo saiu como o esperado. Com a compra da Diklatex, a fábrica em Brusque balançou. A crise mundial de $2008 \mathrm{fez}$ com que o empresário tivesse que tirar recursos da Latina Têxtil para investir na Diklatex.

\section{O bom filho à casa torna}

Como a fruta não costuma cair longe do pé, o sangue empreendedor de Maurício se espalhou por toda a família. Em meio a este cenário de altos e baixos das empresas, o filho mais velho do casal, André, se preparava desde cedo para um dia assumir os negócios da família.

Desde muito novo, sua mãe o levava para dentro da fábrica, onde seu amor pela empresa foi crescendo na mesma proporção que ele. Andre passou por diversos setores da empresa, tanto de setores administrativos como na produção.

Cursou o ensino médio no exterior e voltou para o Brasil para fazer a faculdade de Administração, em Florianópolis. Apesar de ser uma faculdade integral, no período da noite, André também cursava Engenharia de Produção. Mesmo com todo o tempo dedicado aos estudos, Andre sempre esteve em contato com a família e com os negócios, participando das decisões e tendo acesso às informações e resultados para acompanhar a situação das empresas.

Tanta dedicação aos estudos lhe rendeu ser escolhido o melhor aluno nas duas faculdades, ganhando uma bolsa de estudos no Havaí. Estudar lá era um sonho! E além dos estudos, poderia fazer outra coisa que gostava muito: surfar e conhecer lugares novos.

Mas em 2011, o sonho de morar no Havaí foi interrompido por um outro objetivo: ajudar os pais a reerguer as empresas da família. Andre escolheu voltar para o seu berço. Foi neste período que Andre e seus pais conheceram o caos. Naquela época a família tinha apenas um sentimento: esperança. Afinal de contas, a energia era cortada constantemente, máquinas paradas devido à falta de matéria prima, funcionários sem trabalho e a empresa sem dinheiro para as rescisões...

Mas também foi nesse período que Andre pôde colocar em prática todo o seu conhecimento adquirido nas duas faculdades. Afinal de contas, mar calmo nunca fez bom marinheiro. E graças aos estudos de Andre, e a credibilidade que as marcas e a família Jativa tinham no mercado, os clientes acreditaram e começaram a investir nas empresas, adiantando os pagamentos para que fosse possível comprar a matéria prima e receber os produtos posteriormente.

Assim foi a entrada oficial de Andre nos negócios da família. Um começo de muito trabalho, garra e energia para ajudar as empresas a darem a volta por cima. 


\section{Um novo capítulo e um antigo sonho: olhar para as pessoas}

Anos depois o caos começava a passar. Ainda com um passivo muito grande, a família Jativa já podia voltar a respirar normalmente, pois graças aos esforços a situação aos poucos foi se acalmando.

Entre 2012 e 2015 a empresa enfrentou muitos desafios, com resultados negativos em todos esses anos. Em 2016 foi um dos marcos mais importantes das empresas: quando se atingiu pela primeira vez, em anos, um resultado positivo.

Novamente com resultado positivo, em 2017 era hora de virar a página e começar a escrever um novo capítulo. Depois destes anos desafiadores, a família buscou ajuda de consultorias na área de gestão de pessoas e coaching.

Através desta consultoria, a diretoria da empresa, formada pelo Sr. Mauricio, Sra. Jaqueline, Andre e as filhas mais novas, a advogada da empresa Bruna Jativa e a estudante Isabela Jativa, começaram a entender a importância de estabelecer um novo modelo de gestão para o grupo.

Foi neste momento que o antigo sonho do casal de olhar para as pessoas veio à tona. Assim, uma nova cultura de gestão e desenvolvimento de pessoas das empresas se estabeleceu: um modelo de gestão baseado em pessoas e resultados.

Desde então, começaram a investir fortemente no desenvolvimento dos colaboradores, em especial das lideranças, seguidos da padronização dos processos produtivos e administrativos, para garantir que o novo modelo de gestão fosse implantado com sucesso.

Os cursos e treinamentos voltados aos gestores e lideranças, atrelados às ações de endomarketing elaboradas pelo RH começaram a surtir efeitos e aos poucos os resultados desta nova gestão foram aparecendo.

\section{Quando não se sabe onde quer chegar, qualquer caminho serve}

Apesar do forte investimento, tanto de tempo quanto de recursos, na implantação do novo modelo de gestão, alguns gestores das empresas se mostravam insatisfeitos com a falta de direcionamento estratégico das empresas do grupo. Isso também incomodava a família Jativa.

No ano de 2018 foi criado um grupo gerencial formado pelos gerentes da empresa mais a diretoria, formada pela família. Este grupo, intitulado de G14, foi o grande responsável pelo estudo de soluções para os problemas existentes nas empresas.

Através de uma consultoria de um professor e consultor, de uma das melhores escolas de negócios do Brasil, o novo planejamento estratégico das empresas foi elaborado.

Numa primeira etapa, apenas entre a família foi definido o "propósito da família" que é "Viver a missão de empreender; com fé, leveza e responsabilidade pelo resultado. Construir e deixar um legado".

Num segundo momento a família se juntou aos gestores do G14 para a definição das outras questões referentes ao planejamento estratégico. Entre todos os assuntos abordados nessas reuniões, uma das definições mais importantes para a família, e para a empresa, foi a ideologia.

- $\quad$ Nosso Negócio: Soluções para o universo têxtil.

- $\quad$ Nossa Missão: Entregar soluções que gerem valor ao universo têxtil. 
- Nossa Visão (até 2025): Gerar e distribuir riqueza, com excelência e inovação.

\section{- Nossos Valores:}

Resultado: excelência em tudo o que fazemos.

Pessoas: preparadas para o negócio e para a vida.

Paixão: dar significado ao trabalho, com senso de dono.

Inovação: em gestão, processos e soluções.

Humildade: para engrandecer e nutrir nossos relacionamentos.

Simplificação: fazemos mais com menos.

Outras importantes decisões também foram tomadas referente ao futuro das marcas e das empresas. Baseando-se nas estratégias genéricas de Porter, os caminhos para as duas marcas foram definidos. Definiu-se que a Latina seria uma empresa líder em custos e com excelência operacional e a Diklatex seria uma empresa focada na diferenciação. E para se diferenciar em um mercado extremamente competitivo, com grandes players, a inovação é fundamental. O mapa estratégico definido nas reuniões com o G14 é apresentado na Figura 1.

\section{Figura 1 - Mapa Estratégico das empresas Latina e Diklatex}

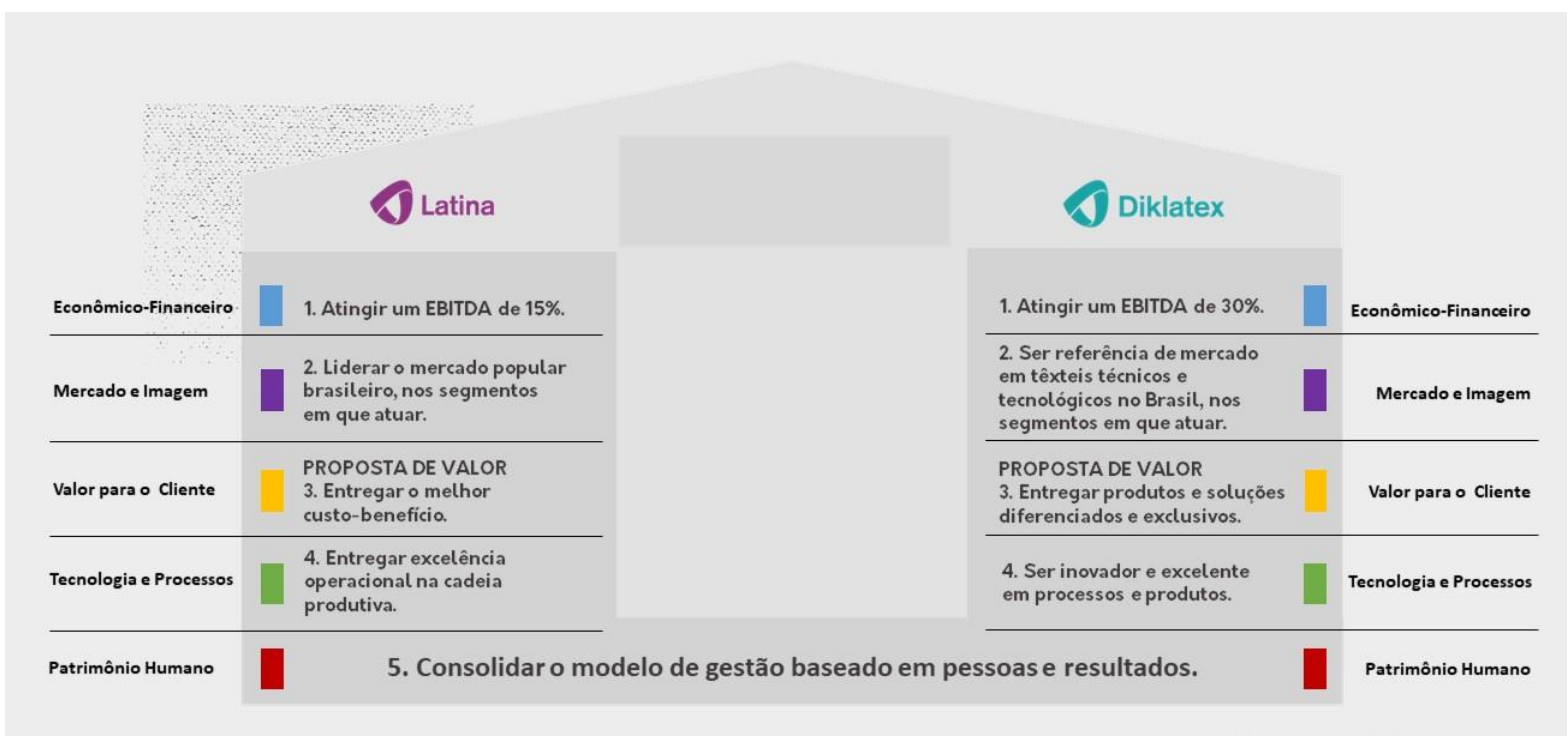

Fonte: Cedido pela empresa

\section{Como se tornar uma empresa inovadora? O dilema pós planejamento estratégico}

O novo Planejamento Estratégico deixou claro para Andre e sua família que para tornar a Diklatex uma empresa inovadora, seja em gestão, processos ou soluções, a cultura e o clima organizacional da empresa também precisariam mudar.

Porém, após muitos anos de crise, com resultados negativos sucessivos, o ambiente não era propício à inovação e a geração de ideias e soluções vindas dos funcionários era tímida. Com o passivo acumulado, por muito tempo a empresa não possuía condições de investir em novos projetos, e isto gerou uma cultura pouco inovadora, onde os funcionários 
não estão acostumados a sugerir e contribuir com novas ideias. Mas, Andre tem certeza que a empresa só será inovadora se os colaboradores forem inovadores.

Interessado neste assunto e com a ideia de implantar uma nova cultura, Andre vem se aprofundando em estudos na área. Descobriu que muitas empresas consideradas inovadoras possuem uma forte cultura intraempreendedora. Esse é o sonho de muitas empresas, e agora se tornou também o sonho de Andre, pois em seus estudos, tem percebido que este tipo de cultura gera uma série de benefícios para as empresas e para os próprios colaboradores.

Andre vem buscando trabalhar uma cultura inovadora primeiramente com seu grupo de gestores, mudando alguns costumes e dando-lhes mais autonomia. Porém, sabe que quanto mais intraempreendedores os gestores se tornarem, mais rápido também deverá ser a mudança de cultura da empresa, em todos os níveis hierárquicos.

E o pior: se os funcionários tiverem um perfil empreendedor e a empresa não os possibilitar o desenvolvimento que almejam, certamente essas pessoas buscarão trabalhar em empresas que os permitam atingir os seus objetivos pessoais. Eis o dilema de André: como tornar a Diklatex uma empresa com cultura intraempreendedora e consequentemente inovadora?

\section{Notas de Ensino}

\subsection{Fonte dos dados}

Utilizou-se fontes primárias de dados para a construção deste caso de ensino, por meio de entrevista em profundidade com Andre Jativa, diretor executivo da empresa, e Mauricio Jativa, sócio fundador. Além disso, a autora principal do caso, é colaboradora da empresa, participando e acompanhando a trajetória do grupo nos seus últimos 5 anos.

\subsection{Objetivos Educacionais}

Com base no relato da trajetória da empresa e as questões para discussão sugeridas, o caso visa atingir aos seguintes objetivos de aprendizagem:

- Discutir a importância do comportamento intraempreendedor e da inovação para as organizações;

- Identificar barreiras e facilitadores à inovação;

- Sugerir mecanismos que promovam o comportamento intraempreendedor e a cultura de inovação na organização.

\subsection{Conexão com a literatura}

\section{Inovação}

O Manual de Oslo (OECD, 2005a, p.55), documento que tem por objetivo padronizar e orientar conceitos, metodologias e apresentar estatísticas e indicadores de pesquisa de inovação e P\&D, define inovação como "é a implementação de um produto (bem ou serviço) novo ou significativamente melhorado, ou um processo, ou um novo método de marketing, ou um novo método organizacional nas práticas de negócios, na organização local de trabalho ou nas relações externas."

Ainda de acordo com o Manual de Oslo, a inovação pode ocorrer em quatro esferas: 
- Inovação de produto: É a introdução de um bem ou serviço novo ou mudanças substanciais nas características e/ou composição de produtos ou serviços existentes.

- Inovação de processo: referem-se às mudanças significativas no método de produção ou de distribuição.

- Inovação organizacional: criação e desenvolvimento de novas formas organizacionais, bem como de mudanças na prática de negócios nos ambientes interno e externo da empresa.

- Inovação de marketing: mudanças no design do produto, mais especificamente na embalagem, no estabelecimento de novos métodos de precificação e na criação de novos mercados.

Outra maneira de categorizar a inovação é entre as práticas incrementais e radicais ou disruptivas. A inovação incremental produz mudanças progressivas que acontecem por meio de melhoria de componentes ou do desempenho de processos, muitas vezes imperceptíveis ao mercado. Já a inovação radical representa uma ruptura com o padrão anterior, originando novas indústrias, novos setores ou mercados, novas demandas e provocando fortes impactos na economia e na sociedade (CANTÚ; ZAPATA, 2006).

Parolin, Vasconcellos e Bordignon (2006), apresentam o Modelo de Avaliação das Barreiras e Facilitadores à Inovação (BFI) - Figura 2, que apresenta condições intraorganizacionais que podem determinar o nível de inovações geradas. Essas condições são divididas em:

- Aspectos do RH e comportamento, envolvendo a gestão estratégica de pessoas, a política de remuneração, o estabelecimento de um clima, a tolerância ao erro e às recompensas por iniciativas inovadoras.

- Aspectos da definição da estratégia, que trata da clareza e da adequação da estratégia, do foco no core competence, da empresa ser regida por princípios ao invés de normas, da cooperação entre áreas e da autonomia e delegação, entre outros fatores.

- Aspectos da gestão tecnológica, diz respeito ao monitoramento das fontes externas, das alianças estratégicas para a inovação e das diretrizes claras em termos de investimentos em tecnologia. 
Figura 2 - Modelo de avaliação de Barreiras e Facilitadores à Inovação

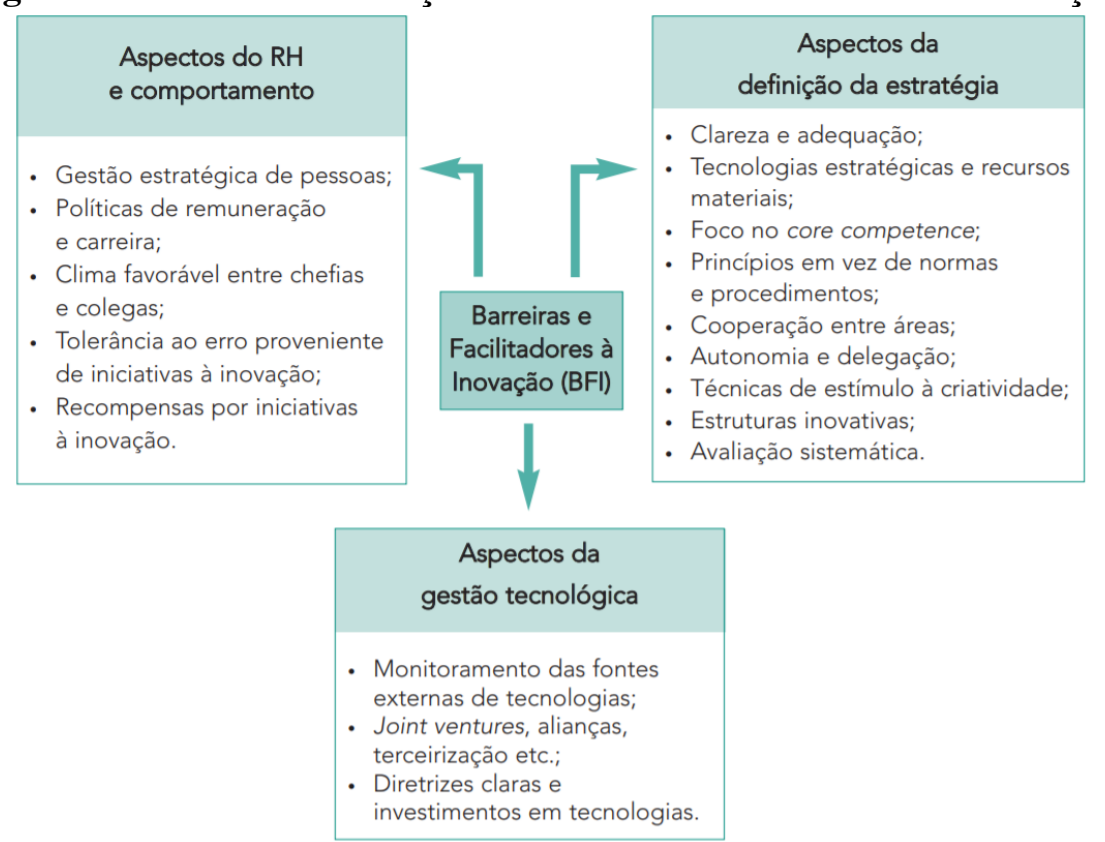

Fonte: Parolin, Vasconcellos e Bordignon (2006, p. 20)

O modelo consiste em uma importante ferramenta de avaliação das práticas organizacionais capazes de fomentar ou dirimir as iniciativas inovadoras. Para Lenzi et al. (2015, p. 122), "o gerenciamento da inovação é uma das tarefas mais desafiadoras das empresas". Isso, segundo os autores, "ocorre porque, em geral, a forma de atuação das corporações é balizada pela busca de resultados planejados. Por outro lado, a inovação exige uma forma de atuação diferenciada, na qual o futuro é desconhecido, mas deve ser revelado".

\section{Intraempreendedorismo}

Para Knox (2002), a inovação contínua está baseada nas capacidades e atitudes das pessoas que trabalham na organização. Essas capacidades e atitudes dependem do encorajamento do empreendedorismo individual e o trabalho em times.

De acordo com Lenzi et al. (2015), a partir da década de 80, autores como Pinchot e Pellman (2004), Seiffert (2005) e Dornelas (2003) dedicaram-se a estudar comportamentos similares entre empreendedores independentes e aqueles profissionais de médias e grandes empresas que de alguma forma exploravam oportunidades e a geração de novos negócios. A partir de então cunhou-se o termo intraempreendedor ou empreendedor corporativo.

Intraempreendedores são aqueles que assumem a responsabilidade pela criação de inovações de qualquer espécie em uma organização (PINCHOT, 2004). Para Hashimoto (2010), o intraempreendedorismo consiste em ações originadas na organização para facilitar o processo de geração de ideias e permitir que as barreiras impostas por estruturas, regras e agentes sejam minimizadas, objetivando a inovação como forma de atingir competitividade (HASHIMOTO, 2010). 
O intraempreendedorismo pode suprir a necessidade constante de inovação eficaz das organizações, proporcionando, inevitavelmente, o aumento da competitividade. Assim, muitos autores especialistas no tema 'competitividade empresarial', "consideram a criação de um ambiente intraempreendedor como fator chave para estimular a inovação e, consequentemente, alcançar o sucesso empresarial" (CHIEH; ANDREASSI, 2008, p. 02).

Hashimoto (2009, p. 25) defende que "todo e qualquer funcionário pode e deve assumir uma atitude empreendedora diante das oportunidades que vislumbra dentro de seu próprio escopo de trabalho, em sua função, em seu departamento ou na própria empresa".

Fernandes et al. (2019) destacam que para se adaptar às mudanças impostas pelo novo modelo econômico, é necessário criar uma organização empreendedora, que inicia pelo apoio da alta gerência, liderando seus colaboradores, tratando os mesmos como parceiros no negócio, valorizando e incentivando a sua participação de maneira alinhada aos objetivos da organização.

Para que isso aconteça, alguns mecanismos precisam ser bem definidos para fomentar a atitude intraempreendedora dos colaboradores. Dornelas (2005), sugere alguns destes mecanismos:

- A empresa deve ter uma visão empreendedora claramente definida e reforçada constantemente;

- Deve haver um sistema de recompensas e reconhecimento aos funcionários, incluindo participação nos resultados

- Incentivar a melhoria do desempenho assumindo riscos calculados, sem penalidades ou punições por falhas;

- Reduzir os níveis hierárquicos e as segmentações de unidade organizacionais;

- Possuir pequenas unidades organizacionais, com equipes multifuncionais;

- Estabelecer papéis variados às pessoas, encorajar/estimular a iniciativa e a experimentação;

- Possibilitar altos níveis de delegação;

- Possibilitar acesso irrestrito à informação;

- Implementar fundos corporativos pra investimento nos novos negócios;

- Trazer para dentro da empresa a voz do consumidor

Cabe destacar que a prática intraempreendedora está relacionada diretamente ao conjunto de competências empreendedoras dos indivíduos que atuam na organização (Lana et al., 2013). Segundo Lenzi et al. (2015), "a base dos estudos sobre empreendedorismo corporativo reside, principalmente, nos aspectos relacionados à inovação e aproveitamento de novas oportunidades. Porém, o estágio de corporação empreendedora é o mais avançado das organizações". Construir uma corporação empreendedora, é um processo que requer o envolvimento de todos, em uma cultura organização voltada à inovação e ao intraempreendedorismo. 


\section{Cultura intraempreendedora}

Cultura pode ser definida como a aprendizagem acumulada e compartilhada por um grupo, envolvendo tanto elementos comportamentais, como emocionais e cognitivos de seus membros. O histórico compartilhado e a necessidade humana por estabilidade, leva a formação de padrões que se denominam cultura (SCHEIN, 2009).

A cultura impregna as práticas e forma um sistema de significações. Atua como um cimento que une os membros em torno dos mesmos objetivos e modos de agir. Caso não tenham suas referências próprias, as organizações ficariam à mercê das convicções individuais de seus membros e sofreriam com a disparidade de procedimentos (SROUR, 2012).

Os padrões de atuação vão sendo transmitidos de funcionário para funcionário, dos mais experientes para os mais novos e tornando-se regras de conduta. Passam a determinar o que é aceitável, o que vale a pena (STOYKO, 2009). Quando a cultura organizacional é forte, a maioria dos colaboradores possui as mesmas opiniões sobre a missão e os valores da empresa e há uma maior estabilidade. Todavia, isso pode ser uma barreira à mudança (ROBBINS; JUDGE, 2012).

Melati e Muniz (2017) apontam que o processo de mudança nos padrões culturais da organização não admite rupturas bruscas, mas transformações adaptativas operadas em vetores essenciais da estrutura. A cultura de uma organização é tomada como uma estrutura de valores bastante complexa, que não somente pode, mas deve ser gerenciada, de tal forma a orientá-la para os objetivos institucionais.

Para desenvolver processos e produtos inovadores que rentabilizem a utilização dos recursos, segundo Lopes et al. (2013), as empresas devem desenvolver uma cultura intraempreendedora. Para os autores, a gestão estratégica e a cultura intraempreendedora andam de mãos dadas, na medida em que a cultura será intraempreendedora na medida em que o intraempreendedorismo fizer parte da estratégia da empresa.

Hartman (2006) criou um instrumento para avaliação da cultura intraempreendedora que classifica as empresas em: a) pouco intraempreendedora, b) medianamente intraempreendedora e; c) intraempreendedora. A autora aponta um conjunto de indicadores de uma cultura organizacional intraempreendedora: comunicação, processo decisório, incentivos/motivação, recompensas, autonomia, liderança, equipes, controle/mensuração, detalhados no quadro 1, a seguir.

\section{Quadro 1 - Os indicadores da cultura intraempreendedora}

\begin{tabular}{|l|l|}
\hline Comunicação & Comunicação fluída entre os mais diversos níveis \\
\hline Processo decisório & Não deve ser centralizado na alta administração \\
\hline Incentivos/motivação & Objetiva gerar entusiasmo nos colaboradores \\
\hline Recompensas & A recompensa a iniciativas de sucesso \\
\hline Autonomia & O intraempreendedorismo deve se manifestar de maneira voluntária entre as pessoas \\
\hline Liderança & Líderes devem promover o empreendedorismo \\
\hline Equipes & A aprendizagem em equipe é essencial \\
\hline Controle/mensuração & Indicadores dos resultados das práticas inovadoras \\
\hline
\end{tabular}

Fonte: Elaborado com base em Hartman (2006)

Para Lana et al. (2013, p. 93), "Empresas com um potencial empreendedor instalado e prática em seus funcionários, pode provocar uma ambientação positiva no sentido de 
contagiar outros funcionários a mesma prática cotidiana”. Desta forma, entende-se que a cultura intraempreendedora é construída pouco a pouco, na medida em que os colaboradores se sintam parte importante do processo de geração de ideais e inovações.

\subsection{Questões para discussão}

2.4.1 Aponte, no caso da Diklatex quais as principais barreiras e os principais facilitadores à inovação, justificando a classificação.

A cultura da Diklatex é pouco intraempreendedora (Hartman, 2006), o que limita o processo de inovação (KNOX, 2002; CHIEH; ANDREASSI, 2008). Contudo, o planejamento estratégico desenvolvido pela diretoria da empresa em 2018 traz maior clareza e adequação da estratégia, foco no core competence e visa uma gestão voltada às pessoas, todos fatores apontados por Parolin, Vasconcellos e Bordignon (2006) como facilitadores à inovação.

Contudo, ainda não há uma política de incentivos e recompensas às práticas de inovação, estruturas inovativas e pouca autonomia é concedida aos colaboradores (PAROLIN; VASCONCELLOS; BORDIGNON, 2006). O planejamento estratégico elaborado apenas pelo grupo denominado G14 de maneira top-down, pode gerar resistência dos colaboradores que devem ser ouvidos em todas as etapas de planejamento estratégico organizacional.

\subsubsection{O fato de a Diklatex ter passado por um processo de fusão vinte e três anos} após a sua fundação e seis anos depois ser adquirida por outro grupo empresarial, influencia de que maneira a cultura organizacional?

A cultura organizacional é formada por padrões de conduta construídos ao longo do tempo, unindo membros de um grupo em torno de um mesmo modo de agir (SCHEIN, 2009; SROUR, 2012). Nesse sentido, as mudanças causadas com os processos de fusão e transferência de propriedade, limitam a estabilidade que os indivíduos buscam na cultura organizacional. A disparidade de procedimentos percebida pode, de certa maneira, confundir e causar conflitos entre os colaboradores (SROUR, 2012). Como pontos positivos, a revisão do planejamento estratégico deixa claro para os colaboradores o propósito da empresa e o conjunto de valores que compõem a cultura. Evidentemente este é um processo de construção, mas o fato de todos os colaboradores terem clareza do que se espera é essencial para a efetivação destas diretrizes. Conforme pregam Melati e Muniz (2017) mudanças nos padrões culturais da organização não admitem rupturas bruscas, visto que há estrutura de valores complexa que deve ser gerenciada. Dessa maneira a integração entre os elementos da cultura organizacional da Diklatex e da Latina devem ocorrer de maneira progressiva.

\subsubsection{Sugira ao mínimo cinco ações para que a empresa desenvolva uma cultura} intraempreendedora e fomente o processo de inovação.

A partir dos facilitadores da inovação propostos por Parolin, Vasconcellos e Bordignon (2006), dos mecanismos de promoção do intraempreendedorismo sugeridos por Dornelas (2005) e dos indicadores da cultura intraempreendedora de Hartman (2006), as ações propostas para que a empresa desenvolva uma cultura intraempreendedora e fomente o processo de inovação podem ser: 
- Reforçar as suas diretrizes estratégicas e a visão empreendedora constantemente

- Criar um sistema de recompensas e reconhecimento aos funcionários que promovam práticas inovadoras bem-sucedidas

- Delegar, dar autonomia e tolerar o erro em práticas inovadoras

- Promover a integração e a melhor comunicação entre as áreas organizacionais, com equipes multifuncionais

- Criar canais para ouvir os clientes e consumidores

- Dar o exemplo por meio das lideranças

\section{Referências}

CANTÚ, Sara Ortiz; ZAPATA, Álvaro R. Pedroza. ¿ Que es la Gestión de la Innovación y la Tecnología (GInnT)?. Journal of Technology Management \& Innovation, v. 1, n. 2, p. 6482, 2006.

CHIEH, Nelson; ANDREASSI, Tales. INTRAEMPREENDEDORISMO: um estudo de caso sobre o entendimento e a aplicação do termo em uma instituição bancária. Revista Eletrônica de Ciência Administrativa, v. 7, n. 2, p. 1-12, 2008.

DORNELAS, Jose Carlos Assis. Empreendedorismo corporativo. Elsevier Brasil, 2005. FERNANDES, Cheila Regina dos Santos; TOMASSONI, Tiago ; GUARESKI, Andreia Helena Pasini; ZACHOW, Marlowa. O intraempreendedorismo como vantagem competitiva: um estudo em uma empresa de transporte rodoviário de passageiros. Empreendedorismo, Gestão e Negócios, v. 8, n. 8, p. 396-413, mar. 2019.

HARTMAN, Adriane et al. Avaliação da cultura intraempreendedora: desenvolvimento e teste de uma metodologia. 2006. Dissertação de Mestrado. Universidade Tecnológica Federal do Paraná.

HASHIMOTO, Marcos. Organizações intra-empreendedoras: construindo a ponte entre clima interno e desempenho superior. Tese (Doutorado em Administração de Empresas) Fundação Getúlio Vargas, São Paulo, 2009.

HASHIMOTO, Marcos; ANDREASSI, Tales; ARTES, Rinaldo; NAKATA, Lina Eiko.

Relações entre intraempreendedorismo, clima organizacional e desempenho financeiro - Um estudo sobre as melhores empresas para se trabalhar no Brasil. EnANPAD XXXIV-

Encontro da ANPAD. Rio de Janeiro/RJ-25 a, v. 29, 2010.

KNOX, Simon. The boardroom agenda: developing the innovative organisation. Corporate Governance: The international journal of business in society, v. 2, n. 1, p. 27-36, 2002. LANA, Jeferson; ORLANDI, Cledir; CAMARGO, Márcio; BRANCO, Marilise Aparecida; LENZI, Fernando César. A relação das competências empreendedoras e da conduta intraempreendedora no setor de serviços educacionais. Revista pensamento contemporâneo em administração, v. 7, n. 2, p. 77-95, 2013.

LENZI, Fernando Cesar; SANTOS, Silvio Aparecido dos; CASADO, Tania; KUNIYOSHI; Márcio Shoiti. Empreendedores Corporativos: Um Estudo Sobre A Associação Entre Tipos Psicológicos E Competências Empreendedoras Em Empresas De Grande Porte De Santa Catarina-Brasil. Revista de Administração, v. 13, n. 2, p. 117-141, 2015. 
MELATI, Claudia; JANISSEK-MUNIZ, Raquel. A cultura organizacional como impulsionadora dos processos de inteligência na gestão pública. Race: revista de administração, contabilidade e economia. Joaçaba, SC. Ed. esp.(2017), p. 131-156, 2017. PAROLIN, Sonia Regina Hierro; VASCONCELLOS, Eduardo; BORDIGNON, João Alberto. BARREIRAS E FACILITADORES À INOVAÇÃO: O CASO NUTRIMENTAL S/A. Revista de Economia Mackenzie, v. 4, n. 4, 2006. PINCHOT, Gifford. Intra-empreendedorismo na prática: um aguia de inovação nos negócios-intrapreneuring in action. Elsevier, 2004.

SCHEIN, Edgar H. Cultura organizacional e liderança. Atlas, 2009.

SROUR, Robert. Poder, cultura e ética nas organizações. Elsevier Brasil, 2012. 